
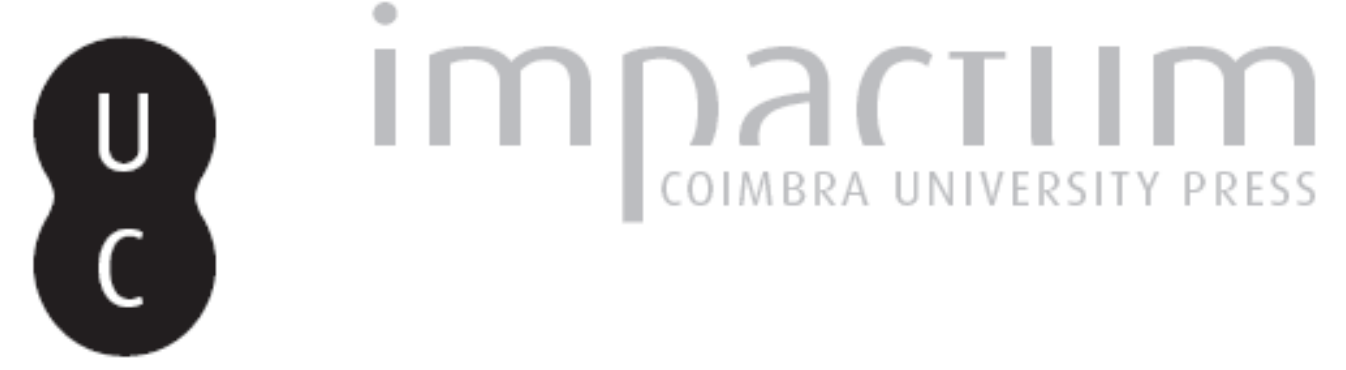

\title{
[Recensão a] James K. Farge, Orthodoxy and Reform in early Reformation France. The Faculty of Theology of Paris. 1500-1543. Série: «Studies in Medieval and Reformation Thought», ed. por Heiko A. Obermann, vol. XXXII
}

\author{
Autor(es): $\quad$ Rodrigues, Manuel Augusto \\ Publicado por: Imprensa da Universidade de Coimbra \\ URL \\ persistente: \\ URI:http://hdl.handle.net/10316.2/45291 \\ DOI: \\ DOI:https://doi.org/10.14195/2183-8925_8-1_31 \\ Accessed : $\quad$ 26-Apr-2023 09:33:35
}

A navegação consulta e descarregamento dos títulos inseridos nas Bibliotecas Digitais UC Digitalis, UC Pombalina e UC Impactum, pressupõem a aceitação plena e sem reservas dos Termos e Condições de Uso destas Bibliotecas Digitais, disponíveis em https://digitalis.uc.pt/pt-pt/termos.

Conforme exposto nos referidos Termos e Condições de Uso, o descarregamento de títulos de acesso restrito requer uma licença válida de autorização devendo o utilizador aceder ao(s) documento(s) a partir de um endereço de IP da instituição detentora da supramencionada licença.

Ao utilizador é apenas permitido o descarregamento para uso pessoal, pelo que o emprego do(s) título(s) descarregado(s) para outro fim, designadamente comercial, carece de autorização do respetivo autor ou editor da obra.

Na medida em que todas as obras da UC Digitalis se encontram protegidas pelo Código do Direito de Autor e Direitos Conexos e demais legislação aplicável, toda a cópia, parcial ou total, deste documento, nos casos em que é legalmente admitida, deverá conter ou fazer-se acompanhar por este aviso.

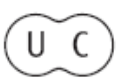


REVISTA DE HISTÓRIA DAS IDEIAS $\mathbf{8}$

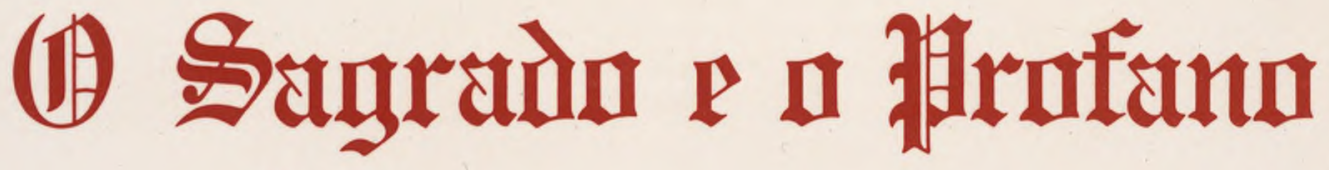 s.1. \\ HOMENAGEM A J. S. DA SILVA DIAS}

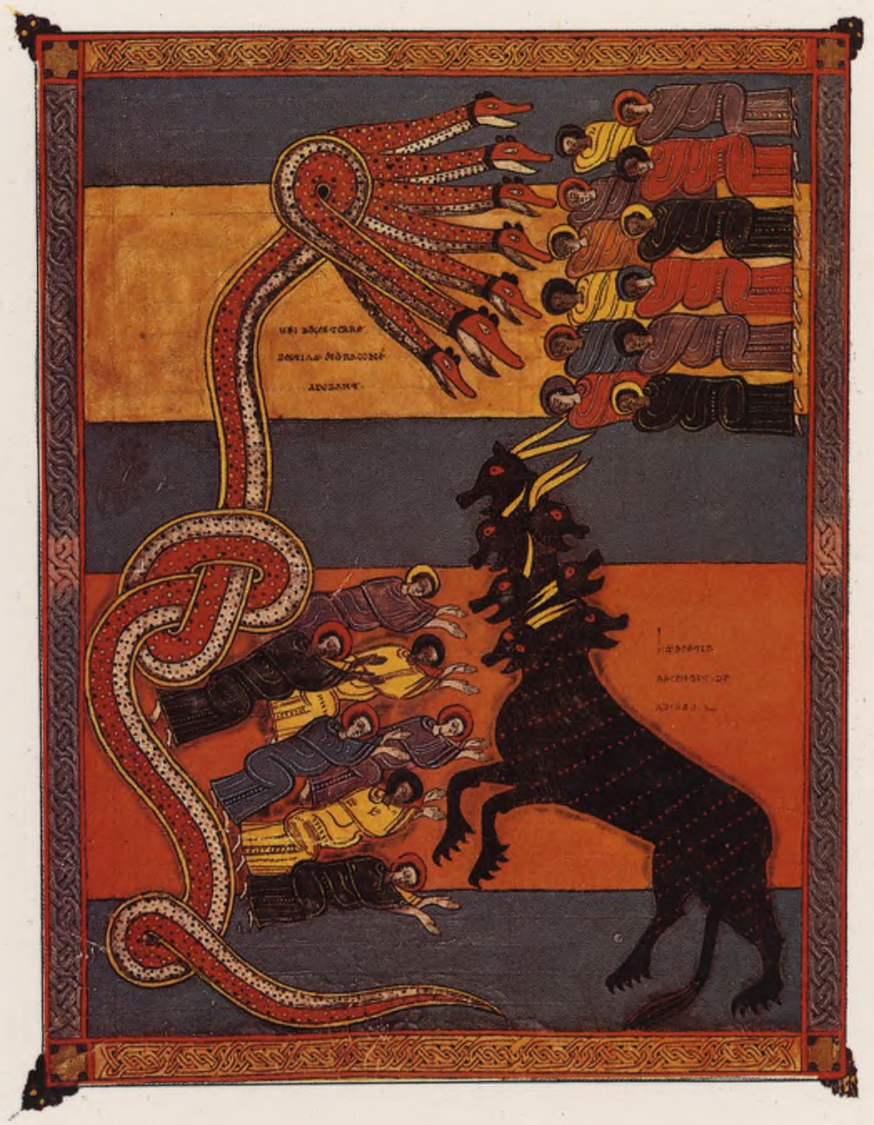

INSTITUTO DE HISTORIA E TEORIA DAS IDEIAS FACULDADE DE LETRAS 
Mirándole, Cabala e Astrologia), os trabalhos sobre o Amor na Itália quinhentista, o Amor em Platão e no neoplatonismo europeu, e um índice dos nomes citados na súmula bibliográfica.

\section{Manuel Augusto Rodrigues}

James K. Farge, Orthodoxy and Reform in early Reformation France. The Faculty of Theology of Paris. 1500-1543. Série: «Studies in Medieval and Reformation Thought», ed. por Heiko A. Obermann, vol. XXXII. Leiden, E. J. Brill, 1985. IX+311 p.

O Parlamento de Paris, em Agosto de 1525, ouviu do jurista Jean Bochard palavras que revelam bem o pensar do tempo acerca da Faculdade de Teologia de Paris: era considerada como uma instituição divinamente inspirada e forte de doutrina e medianeira da verdade de Deus. De facto, a Faculdade havia sido tida durante muito tempo árbitro da fé e depositária da doutrina católica. Os teólogos parisienses assumiam um papel tão notável como os concilios e sínodos, salvaguardadas evidentemente as devidas proporções. $\mathrm{Na}$ Historia Universitatis Parisiensis, de Du Boulay, vol. 6 (París, 1673; reed. Frankfurt-am-Main, 1969), p. 179, e na obra de Pierre Imbart de La Tour, Les origines de la Réforme, vol. 3 (Paris, 1914), p. 206, encontramos documentação comprovativa da importância extraordinária que a Faculdade possuía no domínio do pensamento religioso do tempo. Mas tornava-se necessário elaborar um trabalho que desenvolvesse e justificasse essa peculiaridade. O livro de Pierre-Yves Féret, La faculte de théo logie et ses docteurs les plus célèbres. Époque moderne, 2 vols. (Paris, 1900-1901) não respondia satisfatoriamente àquela questão. Daí o' interesse que o presente estudo de James K. Farge suscita no leitor que, aliás, o segue com a melhor atenção.

As datas escolhidas como «terminus a quo»e «terminus ad quem» (1500 e 1543) encontram a sua justificação no facto de se tratar, quanto à primeira, de um ano considerado ponto de partida da existência de bastantes doutores parisienses que intervêm nas deliberações da Faculdade e, quanto à segunda, de um ano importante na história da mesma por terem aparecido então os famosos vinte e seis Artigos de Fé. O Autor exclui os anos de 1494 e de 1536 como espaço cronológico de abordagem do tema escolhido como havia sido proposto por Henri Bernard-Maître no seu estudo «Les théologastres de TUniversité de Paris au temps d'Erasme et de Rabelais (1496-1536)» publicado em Bibliothèque d'Humanisme et Renaissance, 27 
(1965), pp. 248-264. Em 1494 Erasmo aparecera pela primeira vez em Paris e 1536 foi o ano da sua morte, além de ter sido também então* que se levou a cabo uma importante reforma da Faculdade de Teologia feita pelo Parlamento de Paris, que os primeiros jesuítas saíram da capital francesa e que Calvino publicou as Institutiones Religionis Christianae.

O cap. I da obra é intitulado "Sacratissima Facultas Theologiae: Institution and Organization». As críticas feitas à Universidade de Paris como sendo uma corporação fechada aos ideais humanísticos e às novas concepções artísticas, políticas e religiosas que então surgiam um pouco por toda a parte conheceram nos nossos dias, como já havia sucedido outrora, fautores de renome, como Jacques Le Goff e Jacques Verger, respectivamente em «La conception française de l'université de la Renaissance» (Colloque International à l'occasion du VI ${ }^{\mathrm{e}}$ centenaire de l'Université Jagellonne de Cracovie, 1964, Les Universités européennes du XVI au XVIII e siècle. Aspects et problèmes, Genève, Droz, 1967) ; e em «The University of Paris at the End of the Hundred Years War» (in John Baldwin e Richard Goldhwaite (ed.), Universities and Politics, Baltimore-Londres, 1972). Verger conclui assim a sua análise: «It may be said of our doctors that they lacked true political sense, resisting or rather failing to grap the implications of modern politics, and they were therefore condemned to insufficiency and gradual effacement as a social force». A corroborar a posição de Verger está a obra de Robert Goulet, Compendium de multiplici Parisiensis Universitatis magnificentia, dignitate et excellentia (Paris, Toussaint Denis, 1517), que foi traduzida para inglês em 1928.

Escreve, pois, James Farge: "One of the principal aims of the present book is to point out the difference between the political naiveté of a Robert Goulet and the determined opposition of other doctors to the direction the King and his lawyers were taking France and the French Church. In so doing we shall challenge traditional conclusions about the disappearance of the Paris Faculty of Theology as a force in French affairs» (p. 8).

Ao longo do séc. XV foram não poucos os sinais de decadência da Universidade de Paris mas surgiram ao mesmo tempo tentativas de reforma, como foi o caso dos Colégios de Navarra, de Autun e de Montaigu. Na deste último salientou-se o doutor flamengo de Teologia, Jan Standonck, como foi evidenciado já por Marcel Godet e Augustin Renaudet. E em 1500 a Universidade controlava de novo os assuntos académicos de forma inequívoca: «Teaching flourished and foreign students once again flocked to Paris. This resuscitation of the University 
doubtless allowed Robert Goulet to forget the vicissitudes of past decades. More important, it enabled the University community as a Whole to breathe a sigh of relief».

E a concluir o seu pensamento, diz Farge que o seu livro não pretende ser uma defesa nem uma crítica dos pontos de vista de ordem social, política e teológica da Faculdade de Paris. Pretende sim tirá-la do anonimato para o qual a haviam lançado* os humanistas críticos e os historiadores posteriores. Pretende ainda estudar o papel institucional da Faculdade de Teologia não só em Paris como também em França e no período da Reforma nascente.

A organização da Universidade, os estudos na Faculdade de Teologia, os aspectos financeiros e a reforma de 1536 são alguns dos pontos tratados no cap. I. Uma das causas da reforma foi o conflito já antigo existente entre a Faculdade e o chanceler da Universidade de Paris, o qual abrangia diversos focos de atrito e discordância.

O cap. II apresenta como tema: "Qui sunt isti theologi? A prosopography of Paris graduates, 1500-1536». Noutra obra intitulada Biographical Register of Paris Doctors of Theology, 1500-1536 (Toronto, Pontifical Institute of Medieval Studies, 1980) já James Farge fizera um levantamento exaustivo de todos os estudantes da Faculdade de Teologia da Universidade de Paris que, entre os anos indicados, obtiveram o grau de doutor. Agora limita-se, dado o teor do estudo em causa, a tratar da Faculdade de forma colectiva. São fornecidos quadros gráficos relativos ao clero secular e regular, à proveniência geográfica e social, à preparação pedagógica, ao papel dos teólogos na administração dos colégios e da Universidade, à sua actividade literária e aos benefícios eclesiásticos. No* que respeita à actividade literária, servindo-se não só dos catálogos da Biblioteca Nacional de Paris, do British Museum e do National Union Catalogue como também das obras em publicação, Imprimeurs et libraires parisiens $d u$ XVP siècle e Inventaire chronologique des éditions parisiennes e de outras de reconhecido mérito, o Autor apresenta tábuas bastante elucidativas relativas às edições de livros feitas pelos teólogos parisienses, num total de 101 que publicaram 544 obras em primeira edição. 54 autores publicaram 771 livros com mais de uma edição. Os autores mais prolíferos foram Josse Clichtove (52 títulos), John Mair (39), Pierre Dore (34), Robert Ceneau e Jean Gaigny (31 cada), Juan de Celaya (19), Jérôme de Hangest e Guillaume Pepin (15 cada), Jean d'Abres e Antonio Coronel (14 cada), Francisco de Vitoria (12) e Guillaume Petit (11). Só os dominicanos estão representados entre o clero regular com Dore, Pepin e Vitoria. Quatro teólogos alcançaram um 
total de 405 reedições: Clichtove (210), Pepin (82), Vitoria (61) e Dore (52).

Quanto à temática sobressai a teologia escolástica, seguindo-se a lógica, as obras de piedade, de Sagrada Escritura, de Retórica, Poesia e autores clássicos, de filosofia escolástica, de polémica, sermões, história, biografia, assuntos correntes, patrística e outros. Dominaram John Mair (27) e o seu discípulo Antonio Coronel (11), George Lockhart (9) e David Cranston (8) em lógica. Pierre Dore sobressai nas obras de piedade (25), e na polémica ocupam os primeiros lugares Robert Ceneau, Noël Beda e Jérôme de Hangest com 52\% dos títulos publicados.

Quanto a ordens religiosas domina a dos pregadores: 13 autores e 97 títulos (71\%), seguindo-se os franciscanos, agostinhos, carmelitas, cistercienses, clunienses, beneditinos, premonstratenses, trinitários e cónegos regulares de S. Agostinho.

Surge depois um quadro com a indicação da actividade literária relativa à frequência dos Colégios das Artes e outro respeitante aos Colégios Teológicos. O Autor não esquece de referir ainda a questão epistolográfica, ou seja, que cartas escreveram os doutores teólogos, e de indicar os testamentos deixados pelos mesmos e os bens que possuíam.

O cap. Ill é subordinado ao tema: «Parata semper de Fide reddere rationem: Consultant of Christendom?». Começa o Autor pelas consultas feitas à Faculdade entre 1500 e 1519 (data da disputa de Leipzig de Lutero), passando de seguida à que foi feita acerca do Reformador (1519-1521) e às de 1523-1526 («Five Major Consultations»). James Farge fornece logo no princípio do presente capítulo um texto que é bastante elucidativo, escrito pelos doutores teólogos em 1500: «...officio $\&$ professione parata semper juxta preaceptum principis Apostolorum Petri, omni poscenti de Fide reddere rationem \& nascentibus ubique erroribus diligenter \& fortiter occurrere ad aedificationem militantis Ecclesiae \& Veritatis elucidationem sub correctione sanctissimae matris universalis Ecclesiae ac sacrosanctae Sedis Apostolicae...». Entre os primeiros casos de consulta, conta-se o relativo- à posição de Johan Reuchlin quanto à promoção dos estudos do Talmud, da Cabala e de outras ciências judaicas como sendo essenciais para um recto conhecimento da revelação bíblica, assunto discutido pela Faculdade em 1514-1515. Concordando com os seus colegas de Colónia, os doutores parisienses emitiram em 2 de Agosto de 1514 o seguinte parecer sobre o Augenspiegel: «...dicimus esse respersum multis assertionibus falsis, temeraiis, piarum aurium offensivis, scandalosis, erroneis, Judaicae perfidiae Manifeste fautoriis, sacrosanctis Ecclesiae Doctoribus injuriosis \& contumeliosis, 
incluitum ejusque sponsam Ecclesiam Blasphemis, de haeresi Vehementer suspectis, plerisque haeresix sapientibus \& haereticis nonnullis; ob idaque libellum huiusmodi esse jure supprimendum, de medio tollendum atque igni publice cremandum. Ipsius autem libelli auctorem ad publicam revocationem compellendum non obstantibus glossis quiubuslibet, interpretationibus \& defensoriis nobis hac in re oblatis». As consultas dirigidas à Faculdade acerca de Lutero, do divórcio de Henrique VIII, e de Melanchton merecem ao Autor um interesse particular e são desenvolvidas pormenorizadamente.

Em dois quadros são referidos os teólogos que apoiaram as posições de Henrique VIII (57) e de Catarina de Aragão (52). $\mathrm{O}$ Autor fornece elementos muito concretos acerca de cada doutor. E conclui o presente capítulo com estas palavras: «Was the Faculty of Theology of Paris the Consultant of Christendom?» Not counting the regular consultations with the Parlament of Paris, the more than seventy documented cases in which Kings and princes, bishops, civil and ecclesiastical institutions, and other individuals from many places consulted the Faculty on a wide range of theological and ethical matters is surely asignificant indication that tradition of consulting Paris was still alive and strong and that the Paris Faculty still held a place of importance in the conciousness and consciences of men and institutions».

O cap. IV é consagrado à parte inquisitorial ( $\mathrm{Haec}$ propositio haeretica est: Inquisitor and Teacher»). Os membros da Faculdade deviam prestar o seguinte juramento antes de qualquer acto académico: «In primis protestor quod nichil intendo dicere quod obviet, aut sit dissonum Sacrae Scripturae, aut definitionibus sacrorum conciliorum, aut etiam determinationibus sacrae Facultatis Theologiae matris meae, quibus adhaereo \& semper adhaerere intendo». Fala dos casos de heterodoxia entre 1500-1521 e de Lutero, das questões relativas ao Humanismo e à Reforma (Lefèvre, Berquin, Erasmo e Meaux (1523-1524), às edições e traduções da Bíblia, ao Humanismo e Reforma (1525-1526), aos problemas relativos a Lefèvre e à reforma de Meaux (1525), à Faculdade e Erasmo (1525-1527) e à Faculdade de 1528 a 1532. O Autor passa depois a tratar da Faculdade em 1533-1534, aos artigos de fé da Faculdade (1543) e à censura de livros feita pela mesma. Acerca de cada um deles encontramos um desenvolvimento assinalável que permite uma compreensão perfeita dos assuntos versados e do papel desempenhado pela Faculdade acerca dos temas referidos.

"Notre fille ainée: Relations with other institutions of Church and State» é o tema do cap. V com o qual se encerra a obra. Nele trata o Autor dos seguintes aspectos: a Faculdade 
de Teologia, a monarquia e o papado até 1516, com alusões ao concílio de Pisa - Milão e à concordata de Bolonha; a Faculdade e o Papado (1516-1563); a Faculdade e o episcopado (jurisdição acerca da pregação: o caso de Meaux, os sínodos provinciais, a Faculdade e o bispo Jean Du Bellary); relações com outras Universidades (Paris e Colónia, Paris e Lovaina); e Faculdade, monarquia e o parlamento de Paris (1516-1545). Logo na sua fundação, em 1388, a Universidade de Colónia foi declarada dever reger-se pela de Paris quanto aos estatutos e normas relativas ao professorado e estudantes. O papa Júlio II lembrou precisamente isso em 1508 ao confirmar os privilégios apostólicos de Colónia, declarando que a Universidade havia sido organizada e mantidos os seus privilégios «ad instar studii Parisiensis». Também no que respeita a correntes intelectuais de Paris exerce influência na de Colónia, nomeadamente no que toca ao tomismo e ao nominalismo. As possíveis relações entre Pieter Crockaert e Conrad Kollin, as ligações de alunos e regentes, o problema do grande cisma, de Reuchlin, Lutero, Melanchton e Bucer também são abordadas nesta parte do livro. No que diz respeito às Universidades de Paris e Lovaina já os pontos de contacto são menores, pois o modelo da Faculdade de Teologia lovaniense era Colónia e não Paris. De referir, contudo, entre outros aspectos, que entre os dois teólogos parisienses que primeiro estudaram em Lovaina se conta o célebre Jan Standonck, cuja influência em ambas as Universidades foi fundamental. Jacoby Latomus (Jacques Masson), discípulo daquele em Paris, obteve o doutoramento em Teologia em Lovaina e veio a ser uma das pessoas mais influentes na Universidade até à sua morte em 1544. Outro doutor parisiense, Gillis Van Delft (dout. em 1492), ensinou primeiro em Colónia (1501) e depois em Lovaina (1519) mas passou a maior parte da sua carreira em Paris. Erasmo admirou-o imenso. Pode concluir-se que na primeira parte do séc. XVI a colaboração mútua e a influência entre a Faculdade de Teologia de Paris e as de Colónia e Lovaina foi pequena.

A concluir o seu valioso trabalho, James Farge incluiu uma exaustiva bibliografia com fontes manuscritas e textos publicados e material primário. Quatro índices, um de nomes próprios, outro de autores citados, o terceiro de nomes de terras e o último de tópicos enriquecem bastante esta notável obra de James Farge. 